\title{
LA DECORACIÓN ESCULTÓRICA DE LA PORTADA PRINCIPAL DE LA CATEDRAL DE SEVILLA (1882-1899)
}

\author{
por José Antonio Garcia Hernández
}

Estudio de la decoración escultórica de la Portada Principal. El citado estudio incluye las fases de ejecución y colocación, así como su correspondiente iconografía y un aporte documental referido, por una parte al contrato y carta de pago concemientes a la realización del relieve del tímpano; y por otra parte a los documentos justificativos de los gastos ocasionados en todo el proceso de ejecución y colocación tanto del medallón central como del resto de las esculturas.

A study of the scuptural decoration of the Main Doorway of Seville Cathedral, dealing with the phases of execution and positioning, together with the iconography and an examination of the documentation: firstly the contract and receipt for the relief work on the tympanum, and secondly the documents detailing the expenses involved in the whole process of execution and positioning of the central medallion and the rest of the sculptures.

La portada principal, denominada también de "La Asunción", se halla a los pies de la nave mayor, en el centro de la fachada de poniente del templo catedralicio.

Fue el Cardenal D. Francisco Javier Cienfuegos y Jovellanos, a partir de 1827 , quién se propuso continuar la obra de terminación de la citada porta. En esta etapa, de 1827 a 1831 , el arquitecto responsable del avance de las obras fue D. Fernando Rosales ${ }^{1}$.

Las obras quedaron paralizadas cuando aún no se había realizado la decoración y fue a partir de 1877 cuando comienza una nueva etapa bajo el mecenazgo del Sr. D. Mariano Desmaissieres que dona una casa a la Iglesia situada en la Plaza del Duque de la Victoria, concretamente el número 10, y con el precio de la venta se volvió a proseguir la obra de conclusión de dicha portada ${ }^{2}$. En esta ocasión, el arquitecto encargado de la obra fue D. Joaquín Fernández, firmando el contrato el 23 de Octubre de 1883, donde también se señalaba el tipo de material a utilizar ${ }^{3}$.

1. FALCON MÁRQUEZ, Teodoro: La Catedral de Sevilla. Estudio arquitectónico. Sevilla, 1980. Pág. 97.

2. GESTOSO Y PÉREZ, José: Sevilla monumental y artistica. Sevilla, 1890. Vol. II. Págs. 76 a 79.

3. FALCON MARQUEZ, Teodoro: Ob. cit., pág. 98. 
Cuando la casa se vendió, el problema a resolver era elegir al escultor adecuado que se encargara de la decoración. Se planteó la posibilidad de sacar a concurso la ejecución de la decoración, pero no fue posible, pues en principio el proyecto era colocar setenta y dos esculturas de cuerpo entero y cuarenta y ocho de medio cuerpo, número que no podía costear el Cabildo.

El Deán, en un intento para solucionar la cuestión, escribe al Bibliotecario de la Real Academia D. Aurelio Fernández Guerra, pidiéndole su opinión al respecto. El Deán recibe la contestación el día 5 de septiembre de 1879, donde Fernández Guerra aconsejaba que fuera el escultor D. Ricardo Bellver y Ramón el que ejecutase las esculturas ${ }^{4}$.

Los contactos con Ricardo Bellver fueron muy lentos debido a los viajes que realizaba frecuentemente a Roma, es por lo que el Cabildo se comunicó, en varias ocasiones, con D. Francisco Bellver, padre del artista, para que actuara de intermediario hasta la firma del contrato.

En mayo de 1880 acepta el cargo de dirección de la obra de escultura D. Ricardo Bellver y Ramón, hecho que se tuvo que consultar con la Academia de San Fernando para su aprobación, y el 13 de julio del mismo año llegaba la autorización para que se comenzara cuanto antes ${ }^{5}$.

El 26 de octubre de 1881 se elevaba una petición del presidente de la Comisión de Monumentos Históricos y Artísticos al Cabildo, referente a la reparación de la portada principal ${ }^{6}$, lo cual significaba el comienzo de las obras de decoración de dicha portada, que vió reducido el número de esculturas a ochenta, según había aconsejado la Academia.

Toda la decoración escultórica de la portada la ejecutó el citado R. Bellver en un largo período de tiempo que abarcaría desde 1882 a 1899, año, este último, en el que todavía se estaban recibiendo esculturas ${ }^{7}$.

El proceso de ejecución y colocación de la obra escultórica lo podemos estudiar en dos fases:

a) una fase correspondiente al medallón o relieve del tímpano que decora la ojiva con el tema de la "Asunción de la Virgen", que abarcaría de 1882 a 1885.

b) una segunda fase correspondiente a la realización y colocación del resto de las esculturas (Apóstoles y Santos) que irían colocadas decorando las archivoltas y contrafuertes de la portada y que abarcaría de 1885 a 1899, año este en el que todavía se recibían esculturas, quedando, al final, inconclusa.

4. Archivo de la Santa Iglesia Catedral (en adelante A.S.I.C.). Correspondencia entre Deán y Bibliotecario. 5 de septiembre de 1879 .

5. A.S.I.C. Sección Diversos. N. ${ }^{\circ}$ 48. Comunicación de la Academia. 13 de julio de 1880

6. A.S.I.C. Acta Capitular 26 de octubre de 1881. Fol. 53 vto.

7. A.S.I.C. Sección Diversos. N. ${ }^{\circ} 84$ (50). 


\section{a) Primera Fase}

De la primera fase, correspondiente a la realización y colocación del medallón del tímpano de la portada, sabemos que el 10 de mayo de 1882 se presentan al Cabildo dos modelos para el medallón, realizados por Ricardo Bellver para que dicho Cabildo diera su aprobación y poderlos mandar a la Academia de Bellas Artes de San Fernando ${ }^{8}$. La decisión del Cabildo no se toma en este día, sino en la sesión de 12 de mayo de 1882 , en la que se aprueban los dos modelos anteriormente citados y se autoriza para que se manden a la citada Academia ${ }^{9}$.

Es el 29 de mayo de 1882 cuando la Academia de San Fernando aprueba uno de los bocetos del medallón (boceto $\mathrm{B})^{10}$, enviando la comunicación al Deán el 1 de junio.

El 26 de octubre del mismo año, el Deán comunica al Cabildo la elección de la Academia, y da permiso, el mismo día para que se realice el otorgamiento de contrato público de la obra escultórica con el artista Ricardo Bellver y Ramón ${ }^{11}$.

El 27 de octubre de 1882 se contrató con Ricardo Bellver la ejecución del medallón para la portada, contando la escritura con nueve cláusulas en las que se especificaban las condiciones de la obra, fijándose el pago en 40.000 pesetas, repartidas en cuatro plazos de la siguiente forma: 5.000 pesetas en el momento de la firma del contrato, el segundo, de 10.000 pesetas al término del modelo definitivo; el tercero, de 15.000 pesetas, cuando se colocara el medallón, y el cuarto plazo, de 10.000 pesetas, que se entregaría seis meses después de estar colocado ${ }^{12}$. El 14 de abril de 1884, ante notario, recibe Bellver el segundo plazo por tener acabado el modelo definitivo del medallón ${ }^{13}$, y el 16 de junio del mismo año aprobaba la misma Academia el modelo en yeso ${ }^{14}$.

Cuatro meses más tarde, el medallón se encontraba casi terminado, aunque el escultor pide al Cabildo una prórroga “...por uno o dos meses." para la entrega de dicha obra ${ }^{15}$.

El coste de colocación del medallón se elevó a 7.692 reales como se desprende de la hoja de jornales del expediente de la obra ${ }^{16}$. El término de la colocación se produjo a mediados de mayo de 1885 , según consta en un documento ante

\footnotetext{
8. A.S.I.C. Acta Capitular de 10 de mayo de 1882. Fol. vto. (ver Apéndice Documental N. ${ }^{\circ} 1$ ).

9. A.S.I.C. Acta Capitular de 12 de mayo de 1882. Fol. 91 vto. (ver Apéndice Documental N. ${ }^{\circ} 2$ ).

10. FALCÓN MÁRQUEZ, Teodoro: Ob. cit, pág. 98.

11. A.S.I.C. Acta Capitular 26 de octubre de 1882. Fols. 111-112 (ver Apéndice Documental N.o 3).

12. A.S.I.C. Sección Diversos N. $84(50)$. Sin foliar (ver Apéndice Documental N. ${ }^{\circ} 4$ ).

13. Idem. Documento N. ${ }^{\circ}$ 59: “...que hallándose terminado el modelo definitivo del precitado medallón procedia en cumplimiento de la octava condición de la Escritura del Contrato, hacer entrega al Sr. R. Bellver, de la suma de diez mil pesetas, para la adquisición de piedra y gastos de ejecución...".

14. FALCÓN MÁRQUEZ, Teodoro: Ob. cit. pág. 98.

15. A.S.I.C. Acta Capitular 29 de octubre 1884. Fol. 256 rto.

16. A.S.I.C. Sección Diversos N. ${ }^{\circ} 84$ (50). Documento N. ${ }^{\circ} 96$.
} 
notario de 15 de mayo del mismo año ${ }^{17}$ cobrando Bellver el tercer plazo recogido en la cláusula octava del contrato. Poco tiempo después se colocó la verja que se halla delante de la citada portada ${ }^{18}$; y a los seis meses, es decir, el 15 de diciembre de 1885 , se pagaba a Bellver 10.000 pesetas por el último plazo establecido en el contrato, otorgándose carta de pago el 29 de diciembre del mismo año ${ }^{19}$.

\section{Iconografía}

La composición del medallón sigue totalmente la ley de adaptación al marco, en este caso una forma apuntada. El orden en el que se desarrolla la misma es el siguiente: en el centro se halla la Virgen con los brazos abiertos, enmarcándose en una mandorla sostenida por ángeles, bajo los cuales se hallan otros dos, uno de ellos arroja flores sobre el sepulcro, mientras otro sostiene la losa del mismo. A los pies de la Virgen se halla el sepulcro decorado con una serie de arquillos trilobulados en su intradós y apuntados en el trasdós.

A la izquierda de la Virgen se sitúan una serie de ángeles músicos entre nubes que portan diversos instrumentos musicales. A la derecha de la Virgen, otra serie de ángeles, en su mayoría orantes.

El conjunto se corona con la figura de Dios Padre que bendice con la diestra y porta el cetro en la mano izquierda. A ambos lados de Dios Padre, dos ángeles portan una corona sobre la cabeza de María.

b) Segunda Fase

A la segunda fase, es decir, la que abarca de 1885 a 1899 , corresponde un período de tiempo en el cual se va a intentar la terminación decorativa de la citada portada quedando, como ya citamos, inconclusa.

Por la documentación catedralicia, sabemos que el día 30 de diciembre de $1885^{20}$ se realiza la escritura pública por la que Ricardo Bellver se comprometía a realizar el Apostolado y las demás esculturas de Santos para la portada. En dicha escritura se establecía el tipo de materiales a utilizar (cemento Portland), el número de esculturas (cuarenta), los plazos de tiempo (cuatro estatuas por cada año), el tamaño de las mismas (dos metros y quince centímetros

17. fdem. Documento N. ${ }^{\circ}$ 91: “...dijo el Sr. Arquitecto que hallándose completamente terminada la colocación de dicho medallon con todos los requisitos prevenidos y perfectamente ejecutado el repaso general por el referido Escultor, procedía en cumplimiento de la octava cláusula de la Escritura del Contrato, hacer entrega al Sr. Bellver de la suma de quince mil pesetas, importe del tercer plazo, de los cuatro plazos estipulados...".

18. GESTOSO Y PÉREZ, José: Ob. cit. pág. 79.

19. A.S.I.C. Sección Diversos N. 84 (50) Documento N. 114 (ver Apéndice Documental N. ${ }^{\circ} 5$ )

20. FALCÓN MÁRQUEZ, Teodoro: Ob. cit. págs. 171-172. 
para las de la primera y segunda filas) y su precio correspondiente (seis mil reales, cuatro mil reales para las que midieran entre uno y dos metros y dos mil reales para las menores de un metro).

Gracias a la documentación archivística sabemos la relación de los nombres de los Apóstoles y Santos y su correspondiente fecha de entrega, según se desprende de los recibos de entregas firmados por el propio Bellver y de los informes de transporte y colocación de las mismas ${ }^{21}$ :

\begin{tabular}{|c|c|c|}
\hline 19 Junio 1887 & 18 Мауо 1888 & 15 Febrero 1889 \\
\hline $\begin{array}{l}\text { San Pedro } \\
\text { San Pablo } \\
\text { San Andrés } \\
\text { Santiago el Mayor }\end{array}$ & $\begin{array}{l}\text { San Juan } \\
\text { Santiago el Menor } \\
\text { San Felipe } \\
\text { San Mateo } \\
\text { Santo Tomás }\end{array}$ & $\begin{array}{l}\text { San Matías } \\
\text { San Bartolomé } \\
\text { San Simón } \\
\text { San Bernabé } \\
\text { San Pedro } \\
\text { (en sustitución del } \\
\text { ya colocado). }\end{array}$ \\
\hline 22 Mayo 1890 & 13 Abril 1892 & 17 Junio 1893 \\
\hline $\begin{array}{l}\text { San Marcos: } \\
\text { San Lucas : } \\
\text { San Clemente } \\
\text { San Esteban }\end{array}$ & $\begin{array}{l}\text { San Lorenzo } \\
\text { San Vicente } \\
\text { San Joaquín } \\
\text { San José }\end{array}$ & $\begin{array}{l}\text { Santa Ana } \\
\text { María Magdalena } \\
\text { San Gregorio Magno } \\
\text { San Ambrosio }\end{array}$ \\
\hline 12 Abril 1898 & 10 Agosto 1898 & 13 Mayo 1899 \\
\hline $\begin{array}{l}\text { San Basilio. } \\
\text { San Agustín } \\
\text { San Jerónimo } \\
\text { San Juan Crisóstomo }\end{array}$ & $\begin{array}{l}\text { San Fco. de Sales } \\
\text { San Buenaventura } \\
\text { Santo Tomás de Aquino } \\
\text { San Alfonso María de } \\
\text { Ligorio }\end{array}$ & $\begin{array}{l}\text { San Benito } \\
\text { San Fco. de Asís } \\
\text { San Bernardo } \\
\text { San Pedro Nolasco } \\
\text { Santo Domingo de } \\
\text { Guzmán }\end{array}$ \\
\hline
\end{tabular}

La crítica negativa hacia las citadas esculturas, por parte de algunos sectores intelectuales de la vida artística sevillana, no se hizo esperar; así lo corrobora una petición elevada al Cabildo el día 22 de julio de 1887, en la cual se pedía quitar y reformar dichas imágenes ${ }^{22}$. No obstante, el Cabildo denegó la petición y se continuaron haciendo las estatuas en la forma ya establecida.

21. A.S.I.C. Sección Diversos N. 84 (50) Documentos Núms. 116-138.

22. A.S.I.C. Acta Capitular 22 de julio 1887. Fol. 39 rto. (ver Apéndice Documental N. ${ }^{\circ} 6$ ). 
Otra muestra más de dicha crítica hacia las mismas, la recogía el propio Gestoso en 1890 , donde comentaba que las esculturas no debían haberse ejecutado en piedra artificial (cemento Portland), sino en piedra natural o en barro como las realizadas para las restantes portadas ${ }^{23}$.

La citada crítica no tuvo la fuerza suficiente para poder interrumpir el que se siguieran haciendo dichas imágenes, como lo demuestra el hecho de que en 1899 se seguían recibiendo esculturas ${ }^{24}$.

\section{Iconografía}

Según se observa la portada, la distribución iconográfica es la siguiente:

\section{a) Archivoltas de la zona derecha}

Nos encontramos, en el cuerpo inferior, con parte del Apostolado; así se representan a San Pablo que porta la espada, San Andrés maniatado a la cruz en aspas, un Apóstol en actitud meditativa que porta en su mano izquierda una escuadra (símbolo alegórico de edificar la Iglesia con su predicación) y que se identifica con el Apóstol Tomás; le sigue San Felipe con la cabeza cubierta y portando una cruz que, según la leyenda, hizo desaparecer la serpiente a la que adoraban en Hierápolis y resucitó al hijo del rey; en consecuencia los sacerdotes de la serpiente le crucificaron.

A su izquierda, le sigue la Magdalena con un crucifijo entre las manos y que será, junto a Santa Ana y la Virgen Niña, las únicas representaciones femeninas esculpidas. A continuación de la Magdalena se halla un Santo Obispo que porta un pergamino donde se lee: "TE DEUM", y a sus pies se observa un objeto cilíndrico que representa una maqueta alegórica de la Iglesia, identificándose con San Ambrosio, Padre de la Iglesia, aunque el citado atributo no es privativo del santo obispo, sino común a todos los Doctores de la Iglesia y a los primeros obispos locales. Le sigue la imagen de San Agustín portando el báculo y muestra un libro con la inscripción "DEUS CIVITATE". (Fig. 1).

\section{b) Apilastrado derecho}

En su lateral izquierdo y a modo de continuación de las archivoltas mencionadas, en su cuerpo inferior se ha representado a un Apóstol que porta un pergamino en la mano izquierda y un instrumento de escritura en la derecha, identificándose con Judas Tadeo. A continuación de éste, San Matías que porta un hacha en la mano derecha, símbolo parlante del citado Apóstol.

23. GESTOSO Y PÉREZ, José: Ob. cit., pág. 76.

24. A.S.I.C. Sección Diversos N. ${ }^{\circ} 84$ (50) Documentos Núms. 137-138 (ver Apéndice Documental N. ${ }^{\circ} 7$ ). 
En el cuerpo superior a éste, se representa a otro santo obispo que porta el báculo en su mano izquierda, identificándose con San Basilio, y en la hornacina siguiente Santo Tomás de Aquino, que porta un libro en su mano izquierda, mientras que la derecha señala el corazón, símbolo del amor ardiente a Dios o a la Pasión.

En la zona frontal de este apilastrado, en el cuerpo inferior, se hallan otros dos Apóstoles: a la izquierda uno que sostiene piedras en su manto, tratándose de San Esteban, y a la derecha el Evangelista San Marcos con los símbolos parlantes propios, es decir, el Evangelio en la mano izquierda y un león sedente junto al pie izquierdo. En el cuerpo superior, sobre los mencionados, se encuentra un Santo con hábito y capucha monacales portando una cruz y el báculo en la mano izquierda, identificándose con San Bernardo; y a su izquierda San Francisco de Sales.

En el lateral derecho de este apilastrado, en su cuerpo bajo, se representa San Clemente portando el ancla en la mano izquierda y amarrado, por una soga al cuello, un cartel con la siguiente inscripción: "VICENTI CRISTIANUS", observándose a sus pies un hacha y unos grilletes.

En el cuerpo superior, de izquierda a derecha, se hallan San Francisco de Asís y un Santo fraile que porta un báculo en la mano izquierda, el libro de Reglas en la derecha y cadenas a los pies; dadas las características del escudo de la Orden y los atributos comentados se identifica con Pedro Nolasco. (Fig. 2 b).

c) Archivoltas de la zona izquierda

En el cuerpo inferior y de derecha a izquierda, se hallan representados: San Pedro que porta las llaves, Santiago el Mayor con atuendo de peregrino, San Juan Evangelista que sostiene el Cáliz del que sale la serpiente alada, símbolo del veneno que, según la leyenda áurea, hubo de tomar para demostrar que su predicación era cierta. Le sigue otro Apóstol que porta un libro en la mano derecha y una maza que sostiene con la izquierda, símbolo parlante de Santiago el Menor o Jaime Alfeo.

En el cuerpo superior de las citadas archivoltas, también de derecha a izquierda, se sitúan: San José que porta en brazos al Niño Dios, Santa Ana y la Virgen Niña leyendo, San Gregorio Magno que señala un libro abierto y cuyo símbolo parlante es la paloma que lleva junto a la cabeza representando la inspiración del Espíritu Santo. Concluye esta serie la figura de San Jerónimo que porta una cruz rústica y a los pies un león dormido. (Fig. 1).

d) Apilastrado izquierdo

En el lateral derecho, en su cuerpo inferior, se sitúa el Apóstol San Bartolomé que porta el cuchillo (símbolo del martirio) en la mano derecha y a sus pies un dragón alado encadenado (símbolo de la herejía y de la idolatría). 
A su izquierda otro Apóstol porta una lezna y un pergamino en la mano izquierda, mientras sostiene con la derecha una sierra, símbolo parlante del Apóstol San Simón.

En el cuerpo superior a éste, se encuentra un santo obispo que porta el báculo y en su mano derecha un libro con la inscripción: "HOMILlAS", tratándose de San Juan Crisóstomo, y a su izquierda un santo fraile que porta el hábito de monje y a sus pies, en el suelo, el capelo cardenalicio, símbolo parlante de San Buenaventura.

En el frontal del apilastrado la distribución es la siguiente: en el cuerpo inferior un Apóstol con libro en la mano izquierda, y lanza en la derecha, símbolo este último de varios santos, entre ellos Matías, Simón, Tomás, etc., pero, como parece que se han querido representar en estos cuerpos inferiores de los frontales a los Evangelistas, se trataría de San Mateo. A su izquierda se halla otro Evangelista: San Lucas que porta un pergamino con la inscripción: "S. LUCAS" y se le ha representado escribiendo en el pergamino y con el buey a los pies.

En el cuerpo superior de este frontal, se sitúan un Santo Obispo que porta el báculo en la mano izquierda, identificándose con Alfonso María de Ligorio, y otro santo varón que lleva hábito, báculo y en sus manos un libro; observándose a sus pies un ave que lo identifica con San Benito.

Concluyendo la distribución iconográfica, se ha representado en el lateral izquierdo del citado apilastrado, en el cuerpo inferior, a la derecha, un santo varón que porta en su mano izquierda la palma del martirio, y en la derecha un puñado de piedras, por lo que se identifica con Bernabé. A su izquierda, se halla San Lorenzo que porta también la palma y sujeta una parrilla que llega hasta la base de la imagen.

Por último, en el cuerpo superior, a la derecha se representa un santo con hábito de monje que porta un libro en la mano derecha, y a los pies del mismo se halla un animal mutilado, lo más probable un perro, que eleva una de sus patas delanteras sobre un globo rematado con una cruz, símbolos parlantes en la representación iconográfica de Santo Domingo de Guzmán. (Fig. 2 a).

La distribución de todas las esculturas se corresponde con un programa iconográfico preestablecido y que, resumidamente, es el siguiente: en el cuerpo inferior de las archivoltas se sitúan los Apóstoles; en los frontales de los apilastrados, también en su cuerpo inferior, los Evangelistas y a continuación de los mismos cuatro Santos Mártires. En el cuerpo superior de las archivoltas centrales, la Familia de la Virgen, (Madre, Padre, y Esposo) así como a María Magdalena. A continuación, a ambos lados, los Padres de la Iglesia, seguidos de los Doctores de la Misma; y por último, en los frontales y laterales exteriores de los apilastrados, se han representado, a los Santos Fundadores de Órdenes Religiosas. 
Para finalizar el presente trabajo, señalar que no cabe duda que la envergadura del encargo de esta decoración escultórica puso en una situación difícil al artista, ya que por una parte se le exigía ajustarse al estilo del resto de la fábrica catedralicia, es decir, desarrollar un programa goticista; o bien, la otra solución que le quedaba era elaborar una obra personal, lo cual desentonaría sensiblemente con el conjunto. Ante tal disyuntiva, Bellver optó por una solución intermedia que le condujo hacia una obra ecléctica y un tanto fría, y a pesar de ser un escultor decididamente naturalista no consigue, en esta obra, reflejar tal característica, inclinándose por un particular neogoticismo en la elaboración del relieve central (Fig. 3), y no consiguiendo en el resto de la estatuaria la fuerza realista y dramática propia de otras obras por él ejecutadas (Figs. 4 y 5). Resultado que no es producto de la estilística del escultor, sino de las exigencias, estéticas y materiales, de unas instituciones y de una época que se ancló en el pasado y que, en lo que se refiere al panorama artístico, no destacó especialmente por su nivel creativo. 


\title{
APÉNDICE DOCUMENTAL
}

\author{
Documento N. 1
}

1882. Mayo. Miércoles 10. Sevilla.- Presentación al Cabildo de los dos modelos para el medallón del tímpano de la Portada Principal.

Archivo de la Santa Iglesia Catedral (en adelante A.S.I.C.).

Acta Capitular de 1882. Fol. 90 vto.

"El Sr. Deán presentó al Cabildo dos modelos del medallón que habrá de colocarse en el frontispicio de la Puerta Principal de esta Santa Iglesia, a fin de que si merecían su aprobación, presentarlos enseguida a la Academia de San Fernando, y si como es de esperar los aprueba, empezar la restauración de la Portada. El Cabildo acordó se dé instrucciones para tratar este asunto el viernes próximo".

\section{Documento N. 2}

1882. Mayo. Viernes 12. Sevilla.- Aprobación, por parte del Cabildo de los modelos del medallón para el tímpano de la Portada Principal.

A.S.I.C. Acta Capitular de 1882. Fol. 91 y vto.

"Se dio lectura a la cédula de citación, y el Sr. Dean presentó nuevamente los dos modelos que habia presentado en la sesion anterior, relativos al medallón que había de colocarse en el frontispicio de la puerta principal de esta Santa Iglesia para que el Exmo. Cabildo se sirviese aprobarlo si le parecía bien, a fin de poder recurrir a la Academia de San Fernando para que de los dos elija el que más conforme crea al estilo de la Iglesia. El Cabildo prestó su conformidad para que se recurra a la Academia y esté a los que resuelva la misma como Corporación facultativa".

\section{Documento N. ${ }^{\circ} 3$}

1882. Octubre. Jueves 26. Sevilla.- Comunicación al Cabildo de la elección del modelo de medallón por la Academia de San Fernando, y concesión de permiso para el otorgamiento de contrato al Sr. D. Ricardo Bellver y Ramón.

A.S.I.C. Acta Capitular de 1882. Fols. 111-112.

“...el Sr. Dean dijo, que en consonancia con el acuerdo del Excelentísimo Cabildo, había presentado a la Real Academia de Nobles Artes de San Fernando las dos fotografias de los bocetos hechos por el escultor D. Ricardo Bellver para el medallón de la Puerta Principal de esta Sta. Iglesia, habiendo sido aprobado el señalado con la letra $B$, según comunicación de la Academia de I de junio del año actual, que leyó. Que igualmente y por comunicación del 24 del actual se le había autorizado por la referida Academia para las reparaciones del molduraje deteriorado de la fachada.

En virtud y de acuerdo con la Comisión nombrada por el Exmo. Cabildo para que le acompañe en la ejecución de la obra de la fachada principal de esta Santa Iglesia, deseaba elevar a contrato público por medio de escritura legal, el convenio que tenía concertado con Ricardo Bellver, para la ejecución de las obras bajo pliego de condiciones artisticas y económicas, de que dio lectura, dejando una copia para que obre en la Secretaría de esta Corporación y siendo 
necesario para ello el acuerdo y conformidad del Exmo. Sr. D. Servando Arboli, Dignidad de Capellán Mayor, para que en representación del Exmo. Cabildo y como expresión de la conformidad de éste por su Señoria, asista al otorgamiento de la escritura pública que ha de celebrarse con el Sr. D. Ricardo Bellver. El Cabildo escuchó con suma complacencia el relato del Sr. Dean y acordó estar conformes con todo lo propuesto por su Sria., dando comisión al mencionado Sr. Dignidad de Capellán Mayor para que, en representación del Excmo. Cabildo y de conformidad con el Sr. Dean, otorgue el contrato con el Sr. Ricardo Bellver bajo el pliego de condiciones manifestado. Con lo que concluyó el Cabildo".

\section{Documento N. ${ }^{\circ} 4$}

1882. Octubre. Viernes 27. Sevilla.- Contrato concertado con D. Ricardo Bellver y Ramón indicando las condiciones de ejecución del medallón de la Portada Principal.

A.S.I.C. Sección Diversos. N. ${ }^{\circ} 84$ (50). Sin foliar.

"En la ciudad de Sevilla a viente y siete de Octubre de mil ochocientos ochenta y dos: ante mí D. Ildefonso Calderón y Cubas Notario de esta Capital y de su llustre Colegio comparecen con los testigos que en su lugar se espresarán.

De una parte el llustre Sr. Doctor D. Francisco Bermúdez de Cañas y de la Torre Presbítero, Dean de la Santa Metropolitana y Patriarcal Iglesia Catedral de esta Ciudad vecino de ella, mayor de edad, provisto de cédula personal número ochenta y dos espedida en esta Capital en dos de septiembre último.

$Y$ el Ilustrisimo Sr. D. Servando Arbolí y Farando también Presbítero Dignidad de Capellán, mayor de edad, provisto de cédula personal número cuarenta y espedida en esta Ciudad en dicho dia dos de septiembre, ambos en representación y debidamente autorizados por el Excelentísimo e Ilustrísimo Cabildo Catedral de dicha Santa Iglesia según la certificación que de seguida se unirá, y el Sr. Dean además con el doble carácter de legatario por razón de su cargo del finado Sr. D. Mariano Desmaissieres en el cumplimiento de su obra pia para el exhornado de la puerta principal de dicha Catedral. El certificado que antes se cita es el siguiente que uno en este lugar.

$Y$ de la otra parte comparece el Sr. D. Ricardo Bellver y Ramón escultor y académico correspondiente de las bellas artes de San Fernando, vecino de Madrid, residente en esta Capital que manifestó estar viudo, mayor de edad, provisto de cédula personal número veinte y nueve mil cuatrocientos cuarenta y nueve, espedida en Madrid en catorce de abril del presente año.

Asegurando todos los comparecientes hallarse en la libre administración de sus bienes, pleno goce de los derechos civiles y con capacidad legal por tanto para formalizar toda clase de documentos y contratos y apareciendo asi a mi juicio el Sr. Dean dijo: que en cumplimiento del cargo que le estaba confiado por el Sr. Desmaissieres y despues de cumplidas formalidades que prescribe la legislación vigente, había obtenido con fecha primero de junio de este año de la Real Academia de nobles artes de San Fernando, la autorización competente para poder hacer ejecutar el medallón que debe colocarse en la ojiva de la Puerta Principal de la Catedral, según modelo señalado con la letra $B$ en la fotografia presentada a dicha Academia en unión de otra señalada con la letra $A$, ambos bocetos debidos al escultor Sr. D. Ricardo Bellver.

Que decidido a realizar esta obra y de acuerdo con el Excelentísimo Cabildo según previene la cláusula testamentaria del Sr. Desmaissieres habia convenido su ejecución con el citado Sr. D. Ricardo Bellver cuyo convenio elevan a contrato formal y público por la presente escritura bajo las siguientes bases y condiciones:

Primera.- La parte escultural del medallón será ejecutada en alto relieve con arreglo a la fotografía sacada del boceto en yeso presentada por el Sr. D. Ricardo Bellver, a la Real Academia de nobles artes de San Fernando y aprobada por ésta, según consta en la comunicación del primero de junio del presente año dirigida al Ilustrísimo Sr. Dean compareciente, pudiendo 
sin embargo el artista al desarrollar en grande el pensamiento hacer aquellas correcciones en sus detalles que crea conveniente para obtener mayor belleza y carcícter do estilo.

Segunda.- La piedra que deberá emplearse será análoga a la de la Portada procedente de las canteras de Estepa o de Morón por ser las que presentan mejores condiciones no sólo por prestarse a una esmerada ejecución, sino que también por sus buenos caracteres fisicos y químicos que la asimilan en un todo al tono generral del edificio, circunstancia indispensable para que en el conjunto reine armonía que corresponde.

Tercera.- El referido medallón deberá ejecutarse personalmente por el Sr. D. Ricardo Bellver como único encargado de esta obra, pudiendo sin embargo valerse de los auxiliares que necesite para su más pronta y fácil realización pero siempre bajo su inmediata inspección.

Cuarta.- Antes de la terminación definitiva del medallón se procederá a la colocación de los diferentes trozos que lo constituyen en el sitio correspondiente de la portada del Templo, sujetándolas con grapas de cobre y recibiendo sus puntas con mortero de cal de piedra enlechadas y arena fina de mina, en proporciones iguales, y una vez aseguradas a satisfacción del arquitecto director, se procederá por el escultor a su definitiva y completa terminación, en todas aquellas partes que no haya podido llevarse a efecto en evitación de sus daños por causa de transporte, colocación, etc., siendo de cuenta del escultor entregar el medallón al pie de la obra de la portada.

Quinta.- Serán de cuenta de la administración de la obra los gastos de su colocación contados los medios necesarios a ellos.

Sexta.- Una vez terminado definitivamente el medallón después de colocarlo en su sitio, el Sr. D. Ricardo Bellver lo pondrá en conocimiento del arquitecto director y aprobado que sea por éste participará al llustrísimo Sr. Dean a fin de que disponga si lo creyese oportuno, sea reconocido por una Comisión de la Academia que examinándolo detenidamente y juzgando que la obra ha sido bien egecutada y con arreglo al concepto que entraña el boceto presentado, dé la correspondiente aprobación o en caso contrario haga las observaciones que crea oportunas.

Séptima.- Siendo imposible el poder fijar con precisión el tiempo de la egecución de trabajos artísticos y de gran daño para el buen resultado de ellos por verse con frecuencia obligado el artista a entregar su obra en dia dado sin completarla con el detenimiento que su conciencia le exige, el escultor Sr. Bellver se compromete a realizar la obra en el plazo de dos años a contar desde la fecha de este contrato, pudiéndose prolongar dicho plazo si fuere preciso en gracia de la bondad de la obra previa venia y licencia del Excelentísimo Dean y Cabildo, y siendo en caso que tardase menos una recomendación para el artista.

Octava.- Queda fijada y establecida en cuarenta mil pesetas la cantidad que el Sr. D. Ricardo Bellver percibirá por este trabajo del medallón cuya suma será satisfecha en cuatro plazos y en la forma siguiente: el primero de cinco mil pesetas en el acto de firmarse el presente contrato; el segundo de diez mil pesetas al hallarse terminado el modelo definitivo para la adquisición de las piedras y para atender a parte de los gastos de su egecución en dicha materia; el tercero de quince mil pesetas cuando se reciba el medallón al pie de la obra; y el cuarto y último de diez mil pesetas seis meses despues de colocado en el sitio, y de estar por completo terminado de aquellos retoques que sean necesarios y para responder a los desperfectos intrínsecos en la egecución de la obra.

Novena.- Se estimará el valor del modelo definitivo del medallón en la mitad del importe total de la obra, por cuya razón si por circunstancias imprevistas resultase que el Sr. Bellver no pudiese terminar alguno o algunos de los diferentes trabajos que son consiguientes para llevar a debido efecto la obra, se apreciarán por personas competentes el estado en que se encuentren; abonando en ese caso por quien corresponda la diferencia que resultase en pró o en contra deduciendo las cantidades que hubiere recibido. 
En virtud de lo consignado en las cláusulas anteriores, el Sr. Bellver se obliga a ejecutar la obra referida en el tiempo, por el precio y bajo las condiciones contenidas en el presente documento, y el llmo. Sr. Dean en cumplimiento de lo estipulado en la cláusula octava, entrega en este acto al Sr. Bellver, cinco mil pesetas o sea veinte mil reales, importe del primer plazo de la contrata verificandolo en monedas de oro y plata y billetes del Banco de España de cuya entrega y recibo yo el Notario doy Fé por haber pasado a mi presencia y la de los testigos de esta escritura; y se obliga el mismo Sr. Dean con la personalidad que ostenta a satisfacer el importe de los plazos restantes en las épocas y con las circunstancias expresadas en dicha condición octava, siempre que el artista autor de la obra vaya realizando ésta de la manera proyectada sin interrupción, debiendo en tal caso verificarse los pagos a los plazos establecidos.

El Ilustrísimo Sr. D. Servando Arboli en nombre del Excmo. Cabildo Catedral presta su asentamiento al presente contrato por razón de la intervención que tiene dicha Corporación en la egecución de las referidas obras según cláusula del testamento del Sr. Desmaissieres.

Bajo cuyas cláusulas y bases celebran esta escritura que se obligan a observar y cumplir en todas sus partes según queda establecido y si alguno de ellos faltare ya en el todo o en alguna de sus partes se obligan asi mismo al abono de las costas, gastos, daños y perjuicios que al otro se erroguen designando esta Ciudad como su vecindad para todas las notificaciones y diligencias que puedan tener lugar por consecuencia de este contrato.

Los Sres. otorgantes a quienes yo el Notario doy fé conozco y que son de la profesión y vecindad espresadas lo firman para protocolar en mi Notaría con los testigos de D. Francisco Ramón y Salas y D. José García y Pizarro vecinos de esta ciudad que aseguraron no tener escepción para serlo.

Enterados por mi el Notario los Sres. otorgantes y los testigos del derecho que tienen de leer por si esta escritura lo renunciaron y habiéndosela leído la aprobaron todos de que doy fé.

Siguen las firmas".

\section{Documento N. ${ }^{\circ} 5$}

1885. Diciembre 29. Sevilla.- Carta de pago otorgada a favor del Sr. Deán por la conclusión del medallón del tímpano de la Portada Principal.

A.S.I.C. Sección Diversos. N. ${ }^{\circ} 84$ (50). Documento N. ${ }^{\circ} 114$.

"En la Ciudad de Sevilla a veinte y nueve de diciembre de 1885; ante mi D. Ildefonso Calderón y Cubas, Notario de esta Capital y de su llustre Colegio, comparece con los testigos que en su lugar se espresarán, D. Ricardo Bellver y Ramón escultor y académico correspondiente a las Bellas Artes de San Fernando vecino de Madrid residente en esta capital que manifestó ser de estado casado, mayor de edad, provisto de cédula personal de clase octava número veinte y cuatro mil seiscientos treinta y seis, espedida en Madrid en siete de noviembre del año anterior asegurando hallarse en libre administración de sus bienes de pleno goce de los derechos civiles con capacidad legal por tanto para formalizar toda escritura otorgada ante mí con fecha veinte y siete de octubre de mil ochocientos ochenta y dos contrato con el Ilmo. Sr. Doctor D. Francisco Bermúdez de Cañas y de la Torre, Dean de la Santa Metropolitana y Patriarcal Iglesia Catedral de esta Ciudad y con el llmo. Sr. D. Servando Arboli y Farando, Dignidad de Capellán Mayor de dicha Santa Iglesia con representación y debidamente autorizado por el Excmo. e Ilmo. Cabildo Catedral de la misma Iglesia, la ejecución de un medallón que debía colocarse en la ojiva de la puerta principal de dicha Iglesia y aprabado, según los términos convenidos en la citada escritura y el precio de cuarenta mil pesetas que le serían satisfechas en cuatro plazos y en esta forma: el primero de cinco mil pesetas en el acto de firmarse el presente contrato; el segundo de diezmil pesetas 
al hallarse terminado el modelo definitivo para la adquisición de las piedras y para atender a parte de los gastos de su egecución en dicha materia; el tercer de quince mil pesetas cuando se reciba el medallón al pie de la obra; y el cuarto y último de diez mil pesetas seis meses despues de colocado en el sitio, y de estar por completo teminado de aquellos retoques que fueran necesarios y para responder a los desperfectos intrínsecos en la egecución de la obra; según mas pormenor consta de la citada escritura a que se remite.

Que la obra se ejecutó en efecto en el tiempo calculado, siendo recibido el medallón a satisfacción del llmo. Cabildo Catedral y colocado en el sitio a que se destinaba, y a la vez fue recibiendo las cantidades convenidas en los plazos estipulados, habiéndosele hecho entrega recientemente del importe del último; por lo cual está en el deber de formalizar en beneficio de dicho $S r$. Dean el resguardo correspondiente y poniendolo en ejecución otorgar carta de pago en favor del Ilmo. Sr. Dean de la Santa Iglesia Catedral de esta Ciudad por la cantidad de cuarenta mil pesetas en que fue ajustada la obra referida, cuya suma confiesa y declara haber recibido dicho $S$ r. en las épocas que se fijaron para su entrega y el último plazo antes de este acto, todo en efectivo metálico de que se da entregado a su voluntad renunciando la escepción del dinero no contando prueba del recibo y demás letras a su favor para no valerse de ellas ni de su remedio en ningún tiempo, declarando nulos de ningún valor ni efecto los recibos parciales que ha espedido de las cantidades recibidas y requiriéndome para que, en las escritura al principio citada, estampe la oportuna nota espresiva de quedar pagada en su totalidad la cantidad que alli se menciona como precio de la obra contratada.

En cuyos términos formaliza la presente escritura de carta de pago que se obliga a tener por firme en todo tiempo y a no impugnarla nunca con ningún motivo ni protesto.

El otorgante a quien yo el Notario doy fé conozco y que es de la profesión y vecindad espresada, lo firma para protocolar en mi notaría con los testigos $D$. Joaquín Fernández Arrayagaray y D. Antonio Padura y Junquito vecinos de esta ciudad que manifestaron no tener escepción que les impida serlo.

Enterado por mi el Notario, el otorgante y los testigos del derecho que tienen de leer por sí esta escritura lo renunciaron y habiéndosela yo leido la aprobaron todos de lo cual doy fé=

Ricardo Bellver = Joaquín Fernández = Antonio de Padura = Hay un signo: Ildefonso Calderón".

\section{Documento N. 6}

1887. Julio. Viernes 22. Sevilla.- Petición formulada al Cabildo y denegación de la misma para quitar y reformar las estatuas de la Portada Principal.

A.S.I.C. Acta Capitular de 1887. Fol. 39 rto.

"El Sr. García Valero dijo que había oido a varios artistas de reconocida competencia, que las estatuas que estaban poniendo en la Portada Principal de esta Santa Iglesia no estaban arregladas al arte y ademas eran de pésimo gusto y creía su deber exponerlo en conocimiento del Excmo. Cabildo para que pudiera tomar alguna resolución y por su parte pedia que se mandara retirar las estatuas para que fuesen reformadas. El Sr. Dean como encargado por el testador en invertir el legado destinado para la conclusión de la indicada puerta dijo: que tambien él había oido censurar la obra de la Puerta Principal y no habia hecho caso, por que todo cuanto en ella se habia hecho y se está haciendo ha sido bajo la dirección del arquitecto $D$. Joaquín Fernández y con la aprobación de la Academia de San Fernando, y respecto a las estatuas que se están colocando sólo tiene que decir que han sido encargadass al Escultor Sr. Bellver, que es el mismo que hizo el medallón de piedra que está colocado sobre dicha Puerta, y los diseños o modelos que se presentaron con la debida anticipación a la Academia de San Fernando y ésta los aprobó no de manera ordinaria, 
sino de especial y laudatoria. El Cabildo en vista de la manifestación del Sr. Dean y considerando que el cuerpo facultativo reconocido legalmente en España, es la Academia de San Fernando, acordó que se ejecutase lo que la referida Academia tenga aprobado, y que todo cuanto se haga en adelante sea también aprobación de la misma".

\section{Documento N. ${ }^{\circ} 7$}

1899. Junio. Sevilla.- Resumen de los gastos ocasionados en la obra escultórica de la Portada Principal.

A.S.I.C. Sección Diversos. N. ${ }^{\circ} 84$ (50). Documento sin foliar.

"Documentos justificativos referentes a la obra escultural del medallón para el tímpano de la ojiva de la puerta principal segün contrato formalizado al efecto y gastos concernientes a la colocación.

- 27 Octubre $1882=$ Al escultor D. Ricardo Bellver por el $1^{\text {er }}$ plazo al firmar la escritura, según consta en ella misma

- 11 Mayo 1885 = A Julián Garay, aparejador, encargado de la colocación, por el viaje de ida y vuelta de Madrid a esta Ciudad según justificante $n^{\circ} 90$

- 29 Mayo 1885 = A Rafael Tejada por efectos de cobre y bronce, según justificante $n^{\circ} 94$

Abril $1884=$ Al mismo por el $2^{\circ}$ plazo, acta $n^{\circ} 59$

- 29 Diciembre $1885=$ Al mismo por el $4^{\circ}$ plazo, según consta en la escritura de cancelación, núm. 114

\section{Gastos de colocación}

- 6 Junio $1885=$ Por los jornales invertidos, según justificante número 96

- 12 Junio 1885 = A Guillermo Valera por cemento para sentar y fijar las piezas del medallón, según justificante número 97

- 12 Junio $1885=$ A Antonio Guilena por cal, yeso, arena, etc. según justificante número 98

- 13 Junio $1885=$ A José Solís por jornales y efectos de carpintería, según justificante número 99

- 16 Junio 1885 = A Manuel Groso por efectos de herrería y fundición, según justificante número 100

- 19 Junio $1887=$ Al Sr. Bellver por pago de cuatro estatuas, segün justificante $n^{\circ} 116$

- 6 Julio 1887 = A D. Joaquín Fernández por la colocación de las mismas según justificante $n^{\circ} 117$

- 11 Julio $1887=$ Al Sr. Bellver, recibo $n^{\circ} 118$

- 11 Mayo 1888 = Al mismo por seis estatuas, según recibo número 119

- 4 Julio $1888=A$ D. Joaquín Fernández, cuenta $n^{\circ} 120$

- 15 Febrero $1889=$ Al Sr. Bellver por cuatro estatuas según recibo $n^{\circ} 122$

- 16 Marzo $1889=$ A D. Joaquín Fernández, según cuenta $n^{\circ} 123$ 
- 22 Mayo $1890=$ Al Sr. Bellver por cuatro estatuas, según recibo $n^{\circ} 124$

\begin{tabular}{r|r} 
Reales & Cent $^{\circ}$ \\
24.000 & \\
1.910 & \\
24.000 & \\
2.652 & 96 \\
280 & \\
24.000 & \\
2.024 & 32 \\
136 & \\
24.150 & \\
1.124 & 96 \\
24.154 & \\
1.190 & 12 \\
30.192 & \\
1.492 & 12 \\
\hline 429.127 & 24
\end{tabular}




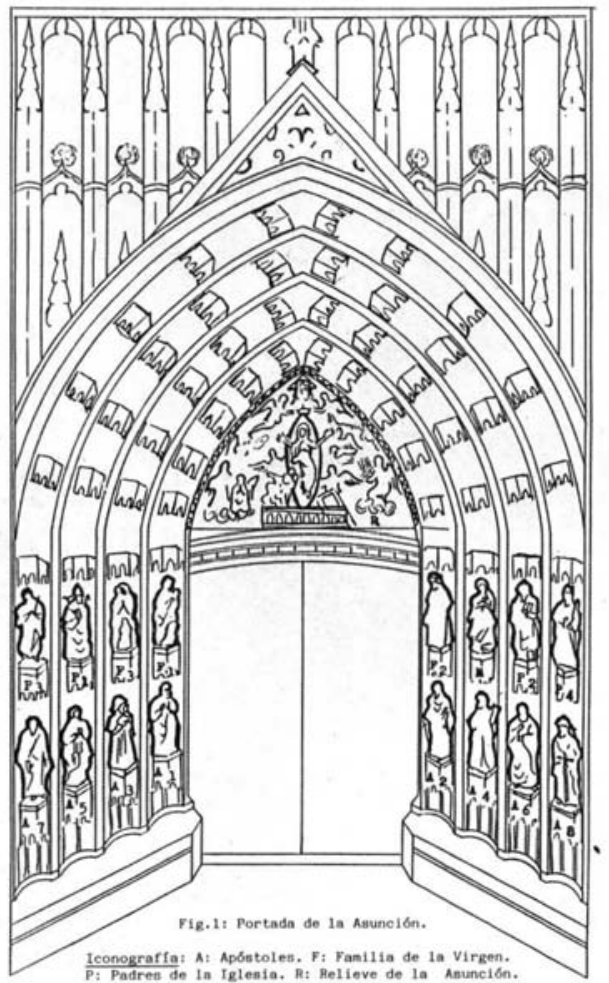

$A_{1}:$ S. Pedro, $A_{2}: S$. Pablo. $A_{3}:$ Santiago Mayor, $A_{4}:$ S. Andrés. A5: S. Juan. $A_{6}:$ Tomf́s. A7: Santiago Mrror $\mathrm{A}_{\mathrm{g}}$ : S. Felipe. $\mathrm{P}_{1}$ : S. Gregorio Magno. P $\mathrm{P}_{2}$ : S. Atroilo. $P_{3}:$ S. Jerónino. $P_{4}: S$. Agustín. M: Marfa Magdalena $F_{1}$ : S. Josê. $F_{2}$ : S. Joaquín. $F_{3}$ : Santa Ana $y$ la Virgen Niศิa.

Figura 1.

Portada de la Asunción. 

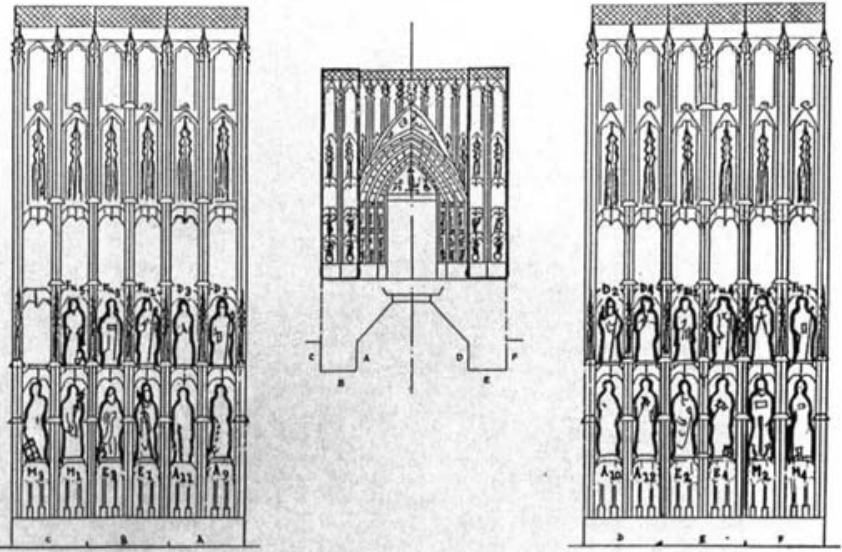

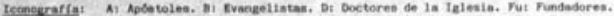

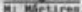

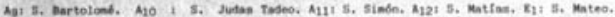

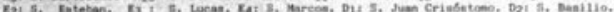

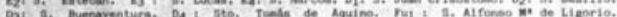

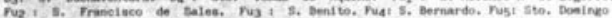

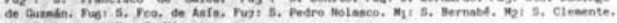
My! 8, Lorenno, Mat S, Vicente.

Figura 2.

Portada de la Asunción. 


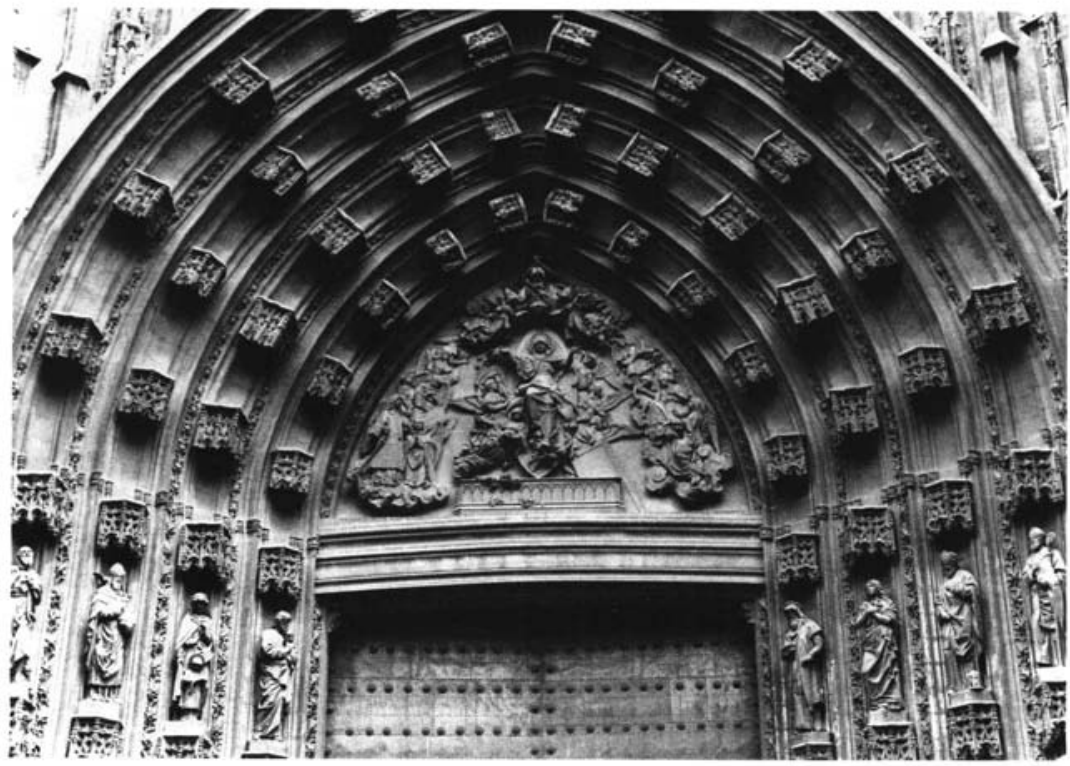




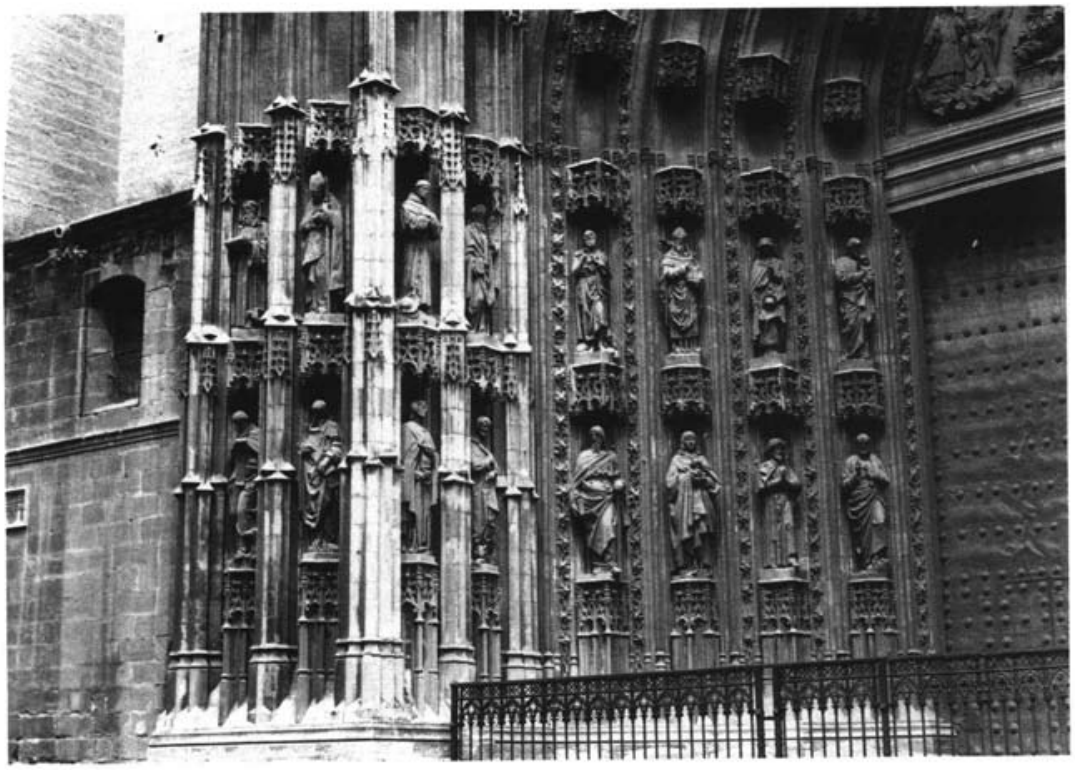




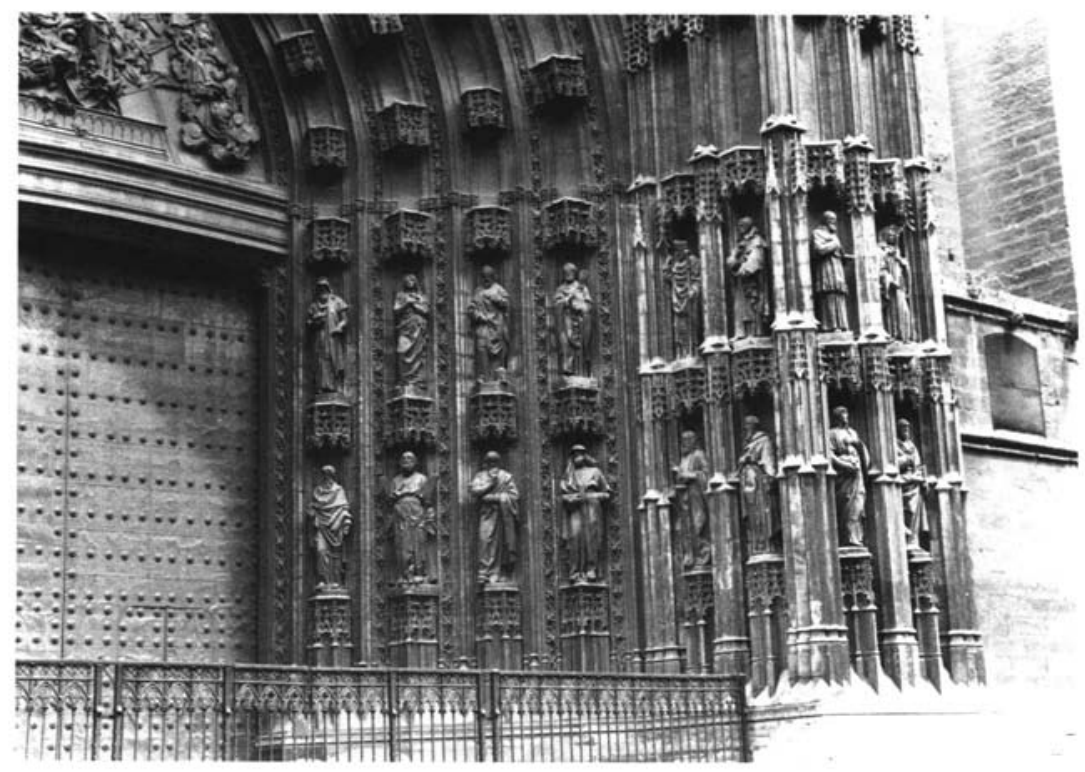

Figura 5 . 